\title{
Laser bidezko ablazioaren egungo egoera eta aplikazioak
}

\author{
(State-of-the-Art of laser ablation and its applications)
}

\author{
Nagore Grijalba ${ }^{1,2 *}$, Fanny Claverie $^{2}$, Ariane Donard ${ }^{2}$, Hélène Tabouret ${ }^{2}$, \\ Christophe Pecheyran ${ }^{2}$, Nora Unceta ${ }^{1}$, M. $^{a}$ Aránzazu Goicolea ${ }^{1}$, \\ Ramón J. Barrio ${ }^{1}$ \\ ${ }^{1}$ Kimika Analitikoa Saila, Farmazia Fakultatea \\ (UPV/EHU)
}

${ }^{2}$ Laboratoire de Chimie Analytique Bio-inorganique et Environnement

(IPREM-UMR UPPA/CNRS 5254)

* nagore.grijalba@ehu.eus

DOI: $10.1387 /$ ekaia.16332

Laburpena: 80ko hamarkadaz geroztik, laser bidezko ablazioa eta akoplamendu induktibozko plasma-masa espektrometria (LA-ICPMS) konbinatzen dituen teknika analitikoa sakonki ikertu eta garatu da, eta, gaur egun, lagin solidoen analisi elemental zein isotopiko zuzena egiteko erreferentziazko teknika bilakatu da. Ezaugarri bereizgarrienak hauexek dira: erabilpen erraza, analisi-denbora laburra, laginari eragindako kalte urriak, sentsibilitate handia eta elementu nagusi zein minoritarioen eta ratio isotopikoen aldibereko neurketa ahalbidetzen duen tarte dinamiko zabala. Lan honetan, LA-ICPMS teknikaren oinarriak eta konfigurazio orokorra azaldu eta femtosegundo/ nanosegundo laser bidezko ablazioaren erabileraren arteko desberdintasun nagusiak nabarmentzen dira. Azkenik, teknika honen egungo egoeraz jabetzeko, jatorri askotariko laginen analisi elementala laburbildu eta berrikusten da biologian eta ingurumenean, osasunean, geokimikan zein auzitegi zientzien alorretan.

Hitz gakoak: Laser bidezko ablazioa (LA), akoplamendu induktibozko plasma-masa espektrometria (ICPMS), femtosegundo, nanosegundo, lagin solidoen analisi zuzena.

Abstract: Since the early 80s, laser-ablation inductively-coupled-plasma mass spec-
trometry (LA-ICPMS) has been widely explored and nowadays is considered to be one
of the most versatile analytical techniques for the direct trace elemental and isotopic
analyses of solid samples. The most remarkable features are ease of use, fast sample
throughput, limited sample damages, high sensitivity and wide dynamic range which
allows the simultaneous acquisition of major and trace elements, as well as the meas- 
N. Grijalba, F. Claverie, A. Donard , H. Tabouret, C. Pecheyran, N. Unceta, M. A. Goicolea, R.J. Barrio

urement of isotope ratios. Throughout this manuscript, the principles and general setup of LA-ICPMS will be extensively explained and the performance of femtosecondLA in comparison to nanosecond-LA discussed. In order to show the state of the art in this field a variety of examples for elemental analysis of solid samples in biological/environmental science, geochemistry and forensic science applications will be presented.

Keywords: laser ablation (LA), inductively-coupled-plasma mass spectrometry (ICPMS), femtosecond, nanosecond, solid sample direct analysis.

\section{SARRERA}

Azken urteotan, laser bidezko ablazioa eta akoplamendu induktibozko plasma-masa espektrometria (LA-ICPMS) konbinatzen dituen teknikak interes bizia piztu du komunitate zientifikoan. Laser bidezko ablazioa masa-espektrometroan lagina sartzeko teknika erabat desberdina da ohiko soluzioen lainoztapen teknikekin alderatuz. Hori dela eta, ikerketa ugari egin dira teknikaren oinarriak hobeto ulertzeko (laser-materia elkarrekintza, aerosolen sorrera eta kuantifikazio metodoak, besteak beste) eta lagin solidoen mikrolaginketa ahalbidetzeko asmoz.

Laser-iturria edozein izanda, laser bidezko ablazioaren eta masa-espektrometroaren arteko lotura erabat erraza da (1. irudia). Lagina hermetikoki itxita dagoen gelaxka batean kokatzen da. Pultsu laburreko eta energia han-

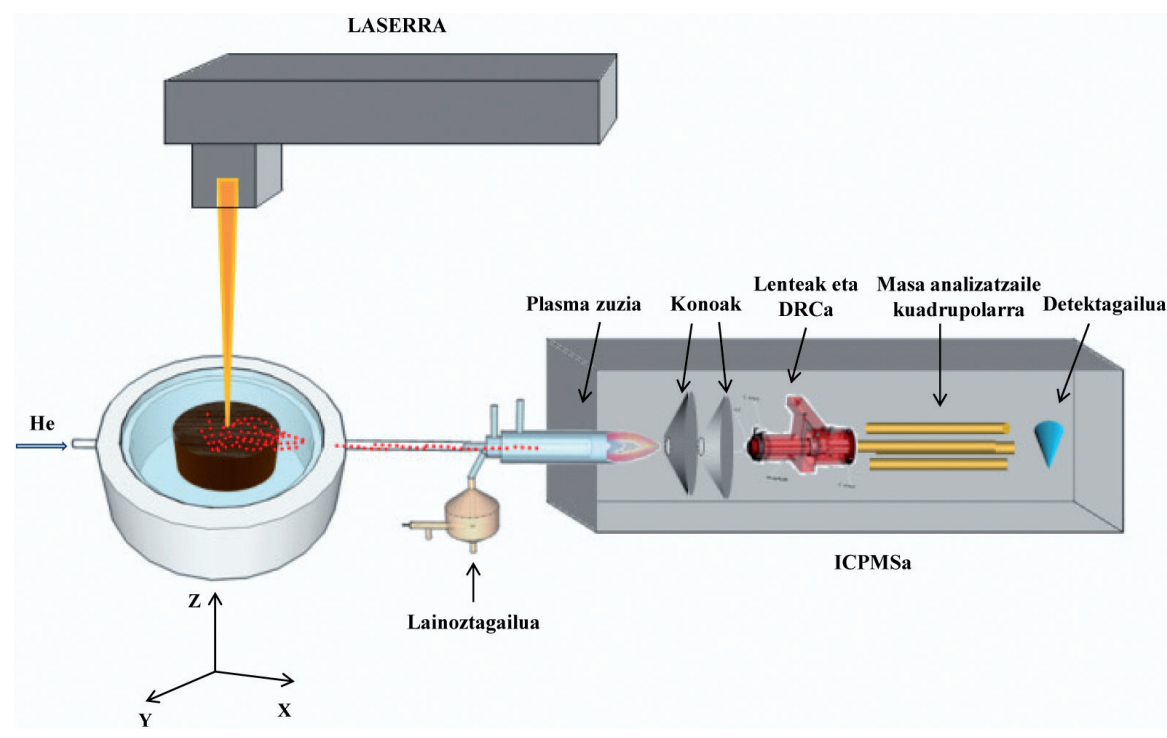

1.irudia. Akoplamendu induktibozko plasma-masa espektrometroari loturiko laser bidezko ablazioaren (LA-ICPMS) eskema. 
Laser bidezko ablazioaren egungo egoera eta aplikazioak

diko laser-izpi bat laginaren gainazalean fokatu eta partikulak, atomoak, ioiak eta elektroiak erauzten ditu. Gas inerte batek (He edo Ar) gelaxka zeharkatu eta ICPMSra garraiatzen ditu. Bertan, aerosola lurrundu, atomizatu eta ionizatu ondoren sortzen diren ioi positiboak masa-espektrometroan analizatzen dira [1]. Hortaz, laserrak lagin solidoaren analisi zuzena ahalbidetzen du, aurretratamendurik gabe eta analisi-denbora nabarmen murrizten da. Gainera, ICPMS teknikak analisi multielemental eta isotopiko azkarra, selektiboa eta sentikorra egiteko aukera eskaintzen du eta parametro horiek masa-espektrometroan hainbat analizatzaile erabiliz hobetu daitezke (kuadrupolo hirukoizdun masa-espektrometroa, masa-espektrometro multikolektorea edo hegaldi-denbora masa-espektrometroa, besteak beste) [2].

Lagin solidoen analisi elementala ICPMS teknikaren bidez egin ohi da lagina bere osotasunean analizatuz (bulk analysis method). Aldez aurretik laginaren mineralizazioa egiten da, non materia suntsitu eta laginaren disoluzioa gertatzen den. Horretarako, ohikoena da azidoen $\left(\mathrm{HNO}_{3}\right.$, $\mathrm{HCl}, \mathrm{HF})$ edota agente oxidatzaileen $\left(\mathrm{H}_{2} \mathrm{O}_{2}\right)$ nahasketak erabiltzea, prozesua bizkortzen duten plaka-berogailuen edo mikrouhinen laguntzaz. Mineralizazio etapa hori luzea eta neketsua da, konplexua eta, askotan, amaigabea [3, 4]. Izan ere, 80ko hamarkadaz geroztik laser bidezko ablazioa lagin-sartze sistema eraginkor eta erakargarria bilakatu da, nekez mineralizatzen diren zenbait material erregogorren (aluminosilikatoak, zeramikak eta kuartzoa, kasu) [5] eta gainerako material solidoen analisi zuzena egiteko [6].

Hori dela eta, gaur egun, laser bidezko ablazioa lehen aukerako teknika analitikoa da material solidoen analisi zuzena egiteko. Alde batetik, ez da beharrezkoa laginaren aurretratamendua egitea eta horrek dakarren denbora luzea eta zeharkako kutsadura saihesten da. Bestalde, analisia aurrera eramateko beharrezkoa den lagin kantitatea txikia da eta, gainera, teknikaren ezaugarri espezifikoen abantailak kontuan izanik, analisiak eskala mikroskopikoan $(5-200 \mu \mathrm{m})$ egin daitezke. Hala ere, laginak oso homogeneoak ez badira, analisiaren adierazgarritasuna bermatzeko sakonera edota gainazal handiagoak analiza daitezke laserraren diametroa, energia eta abiadura areagotuz [7]. Horrela, laser-izpi baten erabilerak mikrolaginketa egitean informazio zehatza eskaintzen du (inklusioak, akatsak, heterogeneotasunak), laginaren gainazalean bereizmen espazial handiarekin fokatu baitaiteke $[8,9]$. 1. taulan ICPMS eta LA-ICPMS tekniken ezaugarriak konparatu dira .

Erakutsitako abantailei esker laser bidezko ablazioa erreferentziazko teknika bilakatu da kimika analitikoaren esparruan lagin konplexuen (material geokimikoak, geruza anizkoitzeko laginak, ingurune-laginak eta lagin biologikoak, artelanak, arkeologia-piezak eta harribitxiak, esaterako) analisi mikroskopikoa egiteko [10-12]. 
N. Grijalba, F. Claverie, A. Donard , H. Tabouret, C. Pecheyran, N. Unceta, M. A. Goicolea, R.J. Barrio

1. taula. ICPMS eta LA-ICPMS tekniken konparazioa [16].

\begin{tabular}{lcc}
\hline Laginaren aurretratamendua & ICPMS & LA-ICPMS \\
\hline Kuantifikazioa & Bikaina & $\begin{array}{c}\text { Zaila, erreferentziazko material } \\
\text { solidoen beharra }\end{array}$ \\
\hline Detekzio-limitea & $0,001-0,1 \mathrm{pg} / \mathrm{g}$ & $0,0001-0,1 \mu \mathrm{g} / \mathrm{g}$ \\
\hline Zehaztasuna & $\% \pm 1-5$ & $\% \pm 1-10$ \\
\hline Bereizmen espaziala & Ez du horrelakorik & $>5 \mu \mathrm{m}$ \\
\hline Sakoneko bereizmena & Ez du horrelakorik & $0,01-9 \mu \mathrm{m}$ \\
\hline Kutsadura arriskua & Altua & Txikia \\
\hline Desabantailak & Interferentziak & Interferentziak, heterogeneotasuna \\
\hline
\end{tabular}

Hala ere, teknika honek badu zehaztasunean eragiten duen desabantaila. Zatikatze elementala (edo elemental fractionation) laginaren matrizearen izaeraren arabera (matrize efektua, hain zuzen) gertatu eta kuantifikazioan eragina duen prozesua da $[13,14]$. Fenomeno hau honela defini daiteke: laserrak eragindako ablazio ez-estekiometrikoa, hau da, erlazio elementalaren eraldaketa ablazioa gertatzen ari den bitartean. Hori dela eta, laser-laginaren elkarrekintzaren ondorioz sortutako aerosola ez da laginaren adierazgarria eta kuantifikazioa eragozten da [15]. Horregatik, laginak berak kuantifikazioan eragin ditzakeen desbiderapenak zuzentzeko laginaren antzeko konposizioa duten erreferentziazko materialak erabiltzen dira (matrix-matching).

Gaur egun, LA-ICPMS teknikaz gain, material solidoen analisi zuzena egiteko beste teknika batzuk daude eskuragarri, esate baterako, laser bidez induzitutako plasma-emisio optikoko espektroskopia (Laser Induced Breakdown Spectroscopy, LIBS), deskarga luminiszente bidezko emisio optikoko espektroskopia (Glow Discharge Optical Emission Spectroscopy, GD-OES), X izpien bidezko espektroskopia fotoelektronikoa (X-Ray Photoelectron Spectroscopy, XPS) eta bigarren mailako ionizazio bidezko masa-espektrometria (Secondary Ion Mass Spectrometry, SIMS) [17] (2. taula). Teknika horiek aurretratamendurik gabeko lagin solidoen analisirako erabiltzen dira. Hala ere, LA-ICPMSaren abantailak nabarmenak dira. Alde batetik, bestelako izaerako eta formako laginei moldatzeko gaitasuna dauka, eta bestetik, zehaztasun eta sentikortasun handiko neurketak azkar egiteko ahalmena eskaintzen du. 


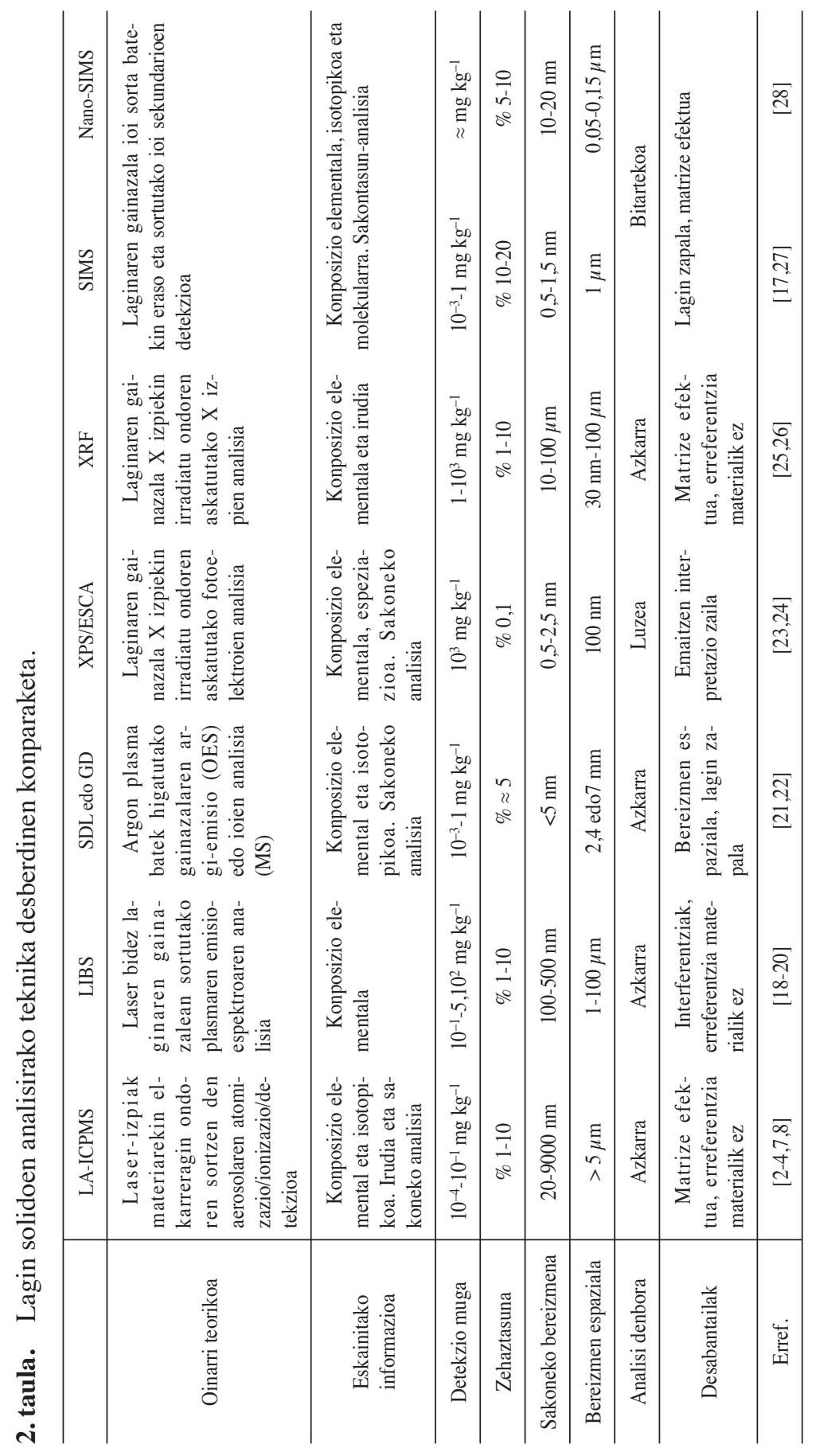

EKAIA, 31 (2017) 
N. Grijalba, F. Claverie, A. Donard , H. Tabouret, C. Pecheyran, N. Unceta, M. A. Goicolea, R.J. Barrio

\section{LASER BIDEZKO ABLAZIOAREN BILAKAERA}

LA-ICPMS teknikaren bidez analisiak modu ezin hobean egiteko lau baldintza bete behar dira: i) laser-lagin elkarrekintza egonkor eta iraunkor mantendu behar da, ii) laginetik askatutako partikulen konposizioa laginaren adierazgarri izan behar du [29], iii) partikulen aerosola modu errazean garraiatu behar da masa-espektrometrora [30] eta iv) akoplamendu induktibozko plasman erabat atomizatu eta ionizatu behar dira aerosolaren osagaiak [7, 13].

Alan Gray-k, 1985. urtean [31], laser bidezko ablazioa garatu zuenetik teknikaren oinarriak ez dira asko aldatu. Hala ere, hobekuntza nabariak egin dira laser-pultsuen iraupenean eta egonkortasunean $[32,33]$, uhin-luzeran (UV-Vis, IR) [34, 35], laser-izpiaren bide optikoaren hobekuntzan eta aerosolaren garraioan (gas garraiatzailearen natura eta fluxua, ablaziogelaxkaren geometria eta bolumena) [36]. Hobekuntza guztien helburua etapa kritikoetan gerta daitezkeen arazoak saihestea da: i) laginak berotzen eta hondatzen direla laserraren eta laginaren arteko elkarrekintzaren ondorioz, ii) aerosola eratzea, iii) aerosolaren garraio desegokia, eta iv) aerosolaren atomizazio/ionizazio/detekzio ez-eraginkorra masa-espektrometroan.

Laser-iturrien azken belaunaldiak, femtosegundo laserrak hain zuzen, $10^{-15}$ segundotan askatzen dute energia. Femtosegundo laserrak nanosegundo laserrak $\left(10^{-9} \mathrm{~s}\right)$ baino milioi bat aldiz azkarragoak dira. Ondorioz, laser-materia elkarrekintza eta ablazio mekanismoak erabat desberdinak dira (2. irudia). Nanosegundo laserrak eragindako efektu termikoek laginaren gainazala kaltetzen dute, laser-izpiak eragin duen gunearen inguruan

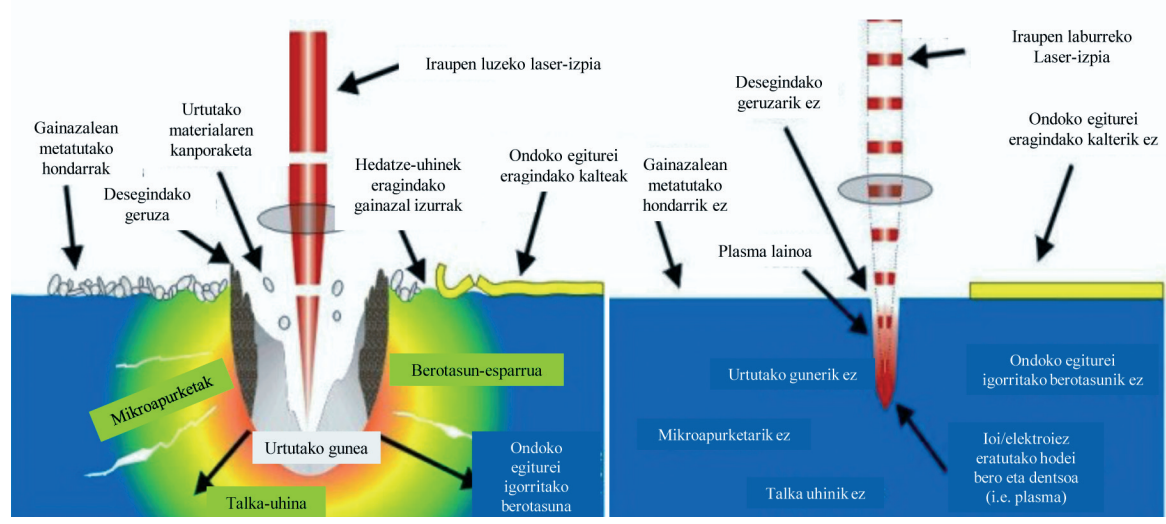

2. irudia. Laser-materia interakzioa a) nanosegundo laser bidezko ablazioan eta b) femtosegundo laser bidezko ablazioan (Clark-MXR, Inc.en baimenarekin erabilitako irudiak). 
Laser bidezko ablazioaren egungo egoera eta aplikazioak

hondarrak metatu eta izurrak azaltzen baitira. Gainera, laser-materia elkarrekintza bortitzak tamaina handiko partikulak erauzten ditu, eta horrek aerosolaren garraioan eta atomizazio/ionizazio/detekzio prozesuetan eragina du. Femtosegundo laserrak, alabaina, efektu termiko mugatuak ditu, eta horrek ia kalterik ez egotea eta neurketaren doitasuna hobea izatea eragiten du [37-39].

Uhin-luzerak zeregin garrantzitsua jokatzen du ablazio prozesuan, laser-materia elkarrekintzan laser-izpiak laginean barneratzeko ahalmena baldintzatzen baitu. Nanosegundo ablazio sistemetan uhin-luzeraren murrizketak, infragorritik $(1.064 \mathrm{~nm})$ argi ultramore ikusgarrira $(157-532 \mathrm{~nm})$, neurketaren zehaztasuna eta errepikakortasuna hobetzen ditu. Uhin-luzeraren eragina femtosegundoko ablazio sistemetan gutxi ikertu da eta ez dago oraindik adostasunik gai honetan [40].

Masa-espektrometroan jasotako seinalea aerosolaren konposizioaren eta banaketa granulometrikoaren naturaren araberakoa da. Horregatik, arreta handia jarri behar zaio partikulen eratze prozesuari, tamainaren araberako banaketari eta konposizioari eta, azkenik, garraioaren eraginkortasunari. Ablazio-gelaxka zeharkatzen duen gas garraiatzailea oinarrizko faktorea da, ablazio prozesuan sortutako beroa disipatu eta aerosolaren homogeneotasunean eragina baitu. Askotan, helioa eta argona erabiltzen dira, baina helioa erabiltzean garraioaren eraginkortasuna hobea da, berezko propietate fisikoak (ionizazio potentziala, masa atomikoa, eroankortasun termikoa, dentsitatea) direla eta [41]. Azkenik, ablazio-gelaxkak bi baldintza bete behar ditu: batetik, aerosol osoaren garraioa ziurtatu behar du seinale/zarata ratio handia eta detekzio-muga baxuak bermatzeko; bestetik, garraioak ahalik eta azkarrena izan behar du (wash-out time balio txikiak) seinaleak bereizmen ona izan dezan [42].

\section{LASER BIDEZKO ABLAZIOAREN APLIKAZIOAK}

Hurrengo orrialdeetan LA-ICPMS teknikaren zenbait aplikazio laburbiltzen dira.

\subsection{Biologia eta ingurumen-zientziak}

Gizakiak planetan utzi dituen aztarnek ekosistema akuatikoen kutsadura ekarri dute. Poluitzaile kimiko ugarik (metal astunak, pestizidak, hidrokarburoak, etab.) arazo fisiologikoak eragin ditzakete organismoetan eta bere onera etortzeko mekanismoak ahuldu. Beraz, ezinbesteko lana da kutsatzaile horien presentzia ezagutzea eta naturan eragin ditzaketen desorekak ikertzea. Hortaz, organismoek ingurumen-faktoreei emandako berehalako erantzunen azterketak (egokitzapen fisiologiko eta jokaera-aldaketak) eta esposizio-markatzaileen bilaketak (ehunetan metatutako poluitzaileen 
N. Grijalba, F. Claverie, A. Donard , H. Tabouret, C. Pecheyran, N. Unceta, M. A. Goicolea, R.J. Barrio

kontzentrazioa, haziera-tasa, aktibitate entzimatikoaren neurketa, etab.) berebiziko garrantzia du. Horretarako, nolanahiko izaera duten xenobiotikoak metatu eta horiei aurre egiteko gaitasuna duten organismoak dira aztergai. Europako aingira (Anguilla anguilla, L.) aurretik aipatutako ezaugarriak biltzen dituen kate trofikoaren goi mailako harrapakaria da, baina desagertzeko arriskuan dago (3. irudia) [43].
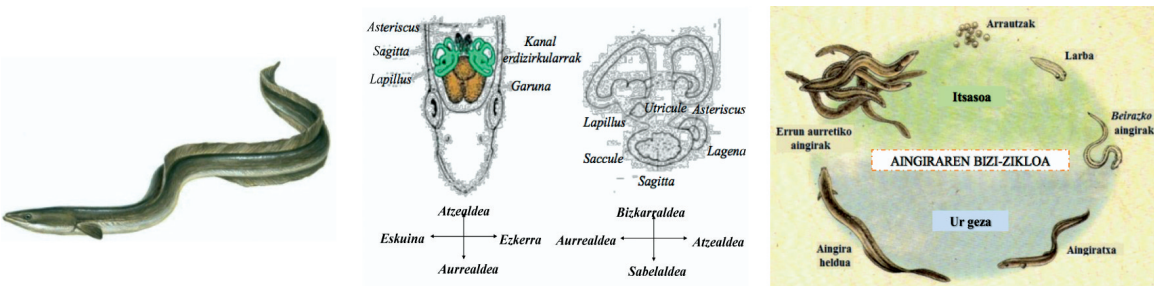

3. irudia. Aingira (Anguilla anguilla, L.) otolitoen kokalekua eta bizi-zikloa.

Izan ere, giza faktore eta baldintza natural ugarik eragin negatiboa dute aingiren populazioan. Horregatik, beharrezkoa da aingiren habitatak identifikatzea migrazio-fenomenoak hobeto ulertzeko eta aingiren populazioaren erreserbak kontrolpean izateko [44,45]. Arlo horretan, otolitoen mikrokimikaren azterketa erabilgarritasun handikoa da. Otolitoak arrain teleosteoen barne-belarrian aurki daitezkeen kaltzifikazio txikiak eta metabolikoki inerteak dira, hazierarekin batera sortzen diren eraztunez osatuak. Izan ere, eraztunak nukleotik $(\mathrm{N})$ ertzera eratzen dira eta hazieraren etapa bakoitzari dagozkion markak ageri dira, itxuraldaketaren markak (MC), hain zuzen (4. irudia) $[46,47]$. Eraztun horiek poluitzaileak harrapatzeko eta me-

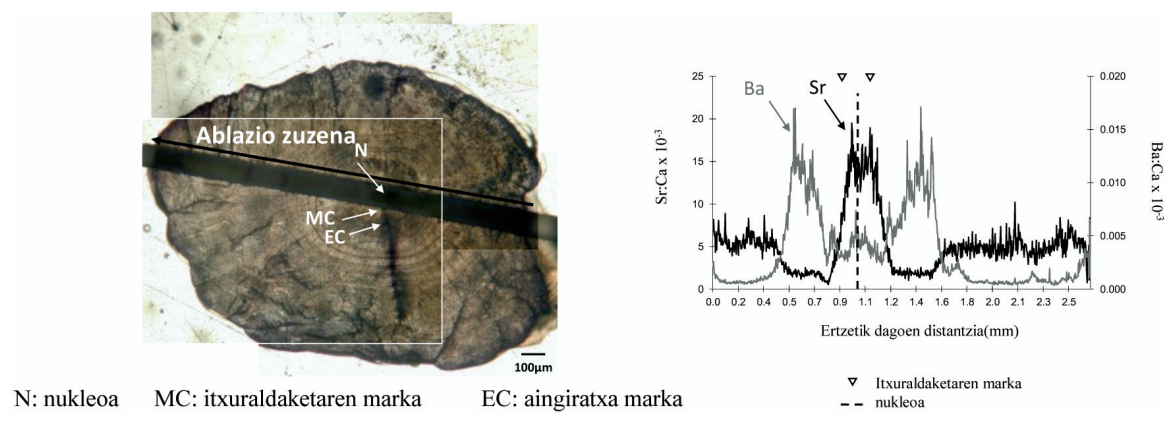

4. irudia. Aingira (Anguilla anguilla, L., Adour ibaia, Frantzia) otolito baten gainazalean egindako ablazio zuzena fsLA-ICPMS bidez eta lortutako seinaleak: Sr:Ca (marra beltza, ur gazian igarotako aldia) eta $\mathrm{Ba}: \mathrm{Ca}$ (marra grisa, ur gezan igarotako aldia) ratioen eboluzio jarraituak aingira nomada batek izandako migrazioa erakusten du. 
Laser bidezko ablazioaren egungo egoera eta aplikazioak

tatzeko ahalmena dute; hortaz, eraztunen konposizio elementala ( $\mathrm{Sr}: \mathrm{Ca}$ eta $\mathrm{Ba}$ :Ca ratioak) arrainek egin duten migrazio-bidea berregiteko baliagarria da $[48,49]$.

Otolitoak ez ezik beste ehun batzuk erabili dira ingurumen-kutsadura aztertzeko (arrain-ezkatak [50], koralak [51] eta oskolak [52]). Ugarte eta lankideek [53], aldiz, atungorrien (Thunnus thynnus) eta atunzurien (Thunnus alalunga) bizkarraldeko hegatseko hezurrak ingurumeneko poluitzaileen bioadierazle gisa erabiltzeko prozedura analitikoa garatu dute. Bizkarraldeko hezurren konposatu nagusia hidroxiapatita $\left(\mathrm{Ca}_{10}\left(\mathrm{PO}_{4}\right)_{6}(\mathrm{OH})_{2}\right)$ da, eta arrainaren haziera erakusten duten eraztunak dituzte. Eraztun horiek urtaroko maiztasuna dute. Udazkenean eta neguan haziera-tasa motelagoa da eta, ondorioz, eraztunak estuak eta zeharrargiak dira. Udaberrian eta udan, aldiz, baldintzak onuragarriak dira hazierarako, eta eraztunak zabalagoak eta opakoagoak dira. Haziera-banda horien eraketa eta biomineralizazioa faktore metaboliko eta ingurumen-faktoreen (klima, migrazioak, elikadura, etab.) menpe dago (5. irudia).

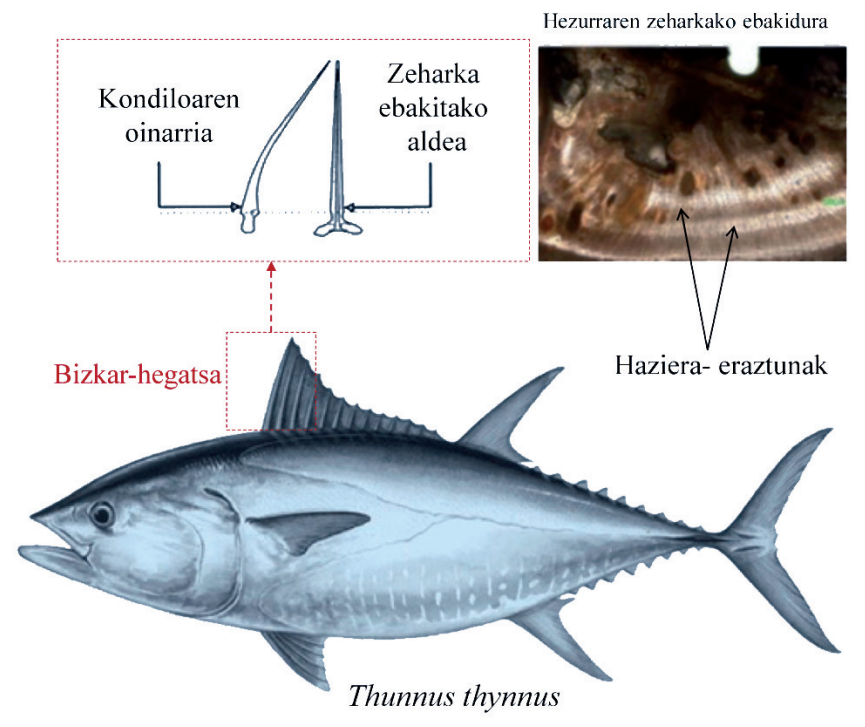

5. irudia. Bizkar-hegatsaren lehenengo hezurraren kokalekua eta zeharkako ebakiduraren argazkia.

Otolitoen laginen prestaketarekin konparatuz, hezurren aurretratamendua errazagoa da, arraina ez baita disekzionatu behar. Prozedura ondorengoa da [54]: aurreko bi hezurren arteko mintza ebaki egiten da eta, ondoren, lehenengo hezurra aurrera eraman eta alde batera eta bestera biratu egiten da. Behin aterata, urarekin garbitu eta lehortzen uzten da. Azkenik, 
N. Grijalba, F. Claverie, A. Donard , H. Tabouret, C. Pecheyran, N. Unceta, M. A. Goicolea, R.J. Barrio

1,3 mm-ko zehar-ebakidura egiten da kondiloaren oinarritik gertu eta beirazko porta batean finkatzen da analizatzeko.

\subsection{Osasun-zientziak}

Metalek ehun biologikoen sekzio finetan duten banaketa irudikatzea edo mapping-a (bioimaging) interes biologikoa duten elementuei buruzko informazio fisiopatologikoa, farmakologikoa eta toxikologikoa eskaintzen duen erronka analitiko berria da $[55,56]$.

Alde batetik, nerbio-sistema metal ugariren itua da. Izan ere, elementu toxikoen presentziak eta metaketak ( $\mathrm{Al}, \mathrm{Cd}, \mathrm{As}, \mathrm{Cr}, \mathrm{Pb}, \mathrm{Tl}, \mathrm{Hg}$ ) prozesu biologikoak kaltetu ditzakete eta heriotza eragin. Aluminioa zahartzaroko dementziaren garapenarekin erlazionatzen da, artsenikoak neuropatia periferikoak eragiten ditu eta talioak potasioa ordezkatzen du eta nerbio-sistema kolapsatzen du, besteak beste. Hori dela eta, metalek garunean duten banaketa-patroia interes handikoa da medikuntzan [57].

Bestalde, zenbait trantsizio-metal ( $\mathrm{Mn}, \mathrm{Zn}$ eta $\mathrm{Cu}$, esaterako) ezinbestekoak dira oinarrizko funtzio fisiologikoak betetzeko. Errezeptoreen eta entzimen parte dira, eta gehienezko edo gutxienezko kontzentrazioa zenbait gaixotasun neurologikorekin erlazionatu da [58], Parkinsonekin [59-61] eta Alzheimerrarekin [62,63], adibidez. Behar-beharrezko elementu horien kantitate txikiak nahikoak dira gorputzaren nutrizio-eskakizunak asetzeko.

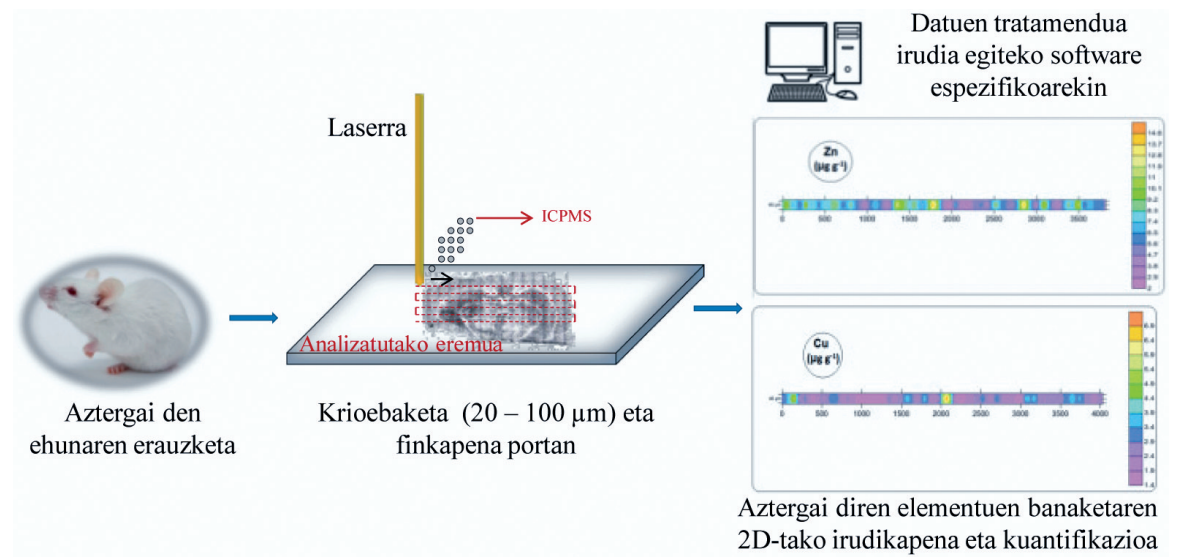

6. irudia. LA-ICPMS bidez mapping-a egiteko jarraitu beharreko prozedura.

Endekapenezko gaixotasunen eta gaixotasun psikiatrikoei buruzko ikerketa egiteko ez ezik, laser bidezko mapping-a onkologian ere erabilgarria den teknika analitikoa da. Kasu honetan, fosforoak berebiziko garrantzia du glikolisia eta azido nukleikoen sintesia bezalako prozesu biologikoetan. 
Laser bidezko ablazioaren egungo egoera eta aplikazioak

Izan ere, adenosin trifosfatoaren (ATP) sintesirako eta arnasketa-katean gertatzen den fosforilazio oxidatiborako ezinbestekoa da. Tumoreek energia-eskakizun eta glikolisi-tasa handia dute [64]. Hortaz, elementu ez-metaliko horren banaketa irudikatzea lagungarria izan daiteke tamaina txikiko tumoreen diagnostiko-erreminta gisa.

Halere, metalek ehun biologikoetan duten banaketa irudikatzearen arrazoia edozein izanda, jarraitu beharreko urratsak parekoak dira kasu guztie$\tan$ [65] (6. irudia). Lehendabizi, 20 eta $100 \mu \mathrm{m}$ tarteko lodiera duten ehun sekzio finak kriotomoarekin $\left(-20^{\circ} \mathrm{C}\right)$ moztu eta portan finkatzen dira. Zenbait ikerlarik lagin biologikoen analisia egiteko ablazio-gelaxka kriogenikoak [66] garatu dituzte ablazio prozesua hobetzeko asmoz. Behin lagina gelaxkan dagoela, laser-izpia laginaren gainean fokatzen da eta interesekoa den eremua ablazionatu egiten da. Azkenik, bioimaging egiteko programen laguntzaz, datuak tratatzen dira, elementuen banaketa erakusten duten irudiak eraikitzeko.

\subsection{Geokimika}

Aztarna elementuen eta isotopoen determinazioek garrantzizko zeregina betetzen dute petrolio-industrian. Izan ere, agente trazatzaile gisa erabil daitezke petrolio-petrolio edo petrolio-iturburu korrelazioa ezartzeko. Nikela eta banadioa, elementu metaliko arruntenak petrolio gordinean, zabalki erabili dira petrolioaren eta petrolio-hobiaren arteko erlazioa aztertzeko eta biodegradazio maila ezagutzeko. Gainera, berunaren analisi isotopikoak petrolioaren jatorriari buruzko informazioa eskaintzen du (mantu, lurrazal edo giza jatorria) eta Renio-Osmio erlazioa geokronometro gisa erabil daiteke petrolio gordinaren kanporatze-data kalkulatzeko. Petrolioaren miaketatik aparte, metalak interes handiko aztergaiak dira petrolioaren produkzio eta fintasun prozesuan korrosioari, katalizatzaile kimikoen kutsadurari eta poluzioaren kontrolari dagokienez [67].
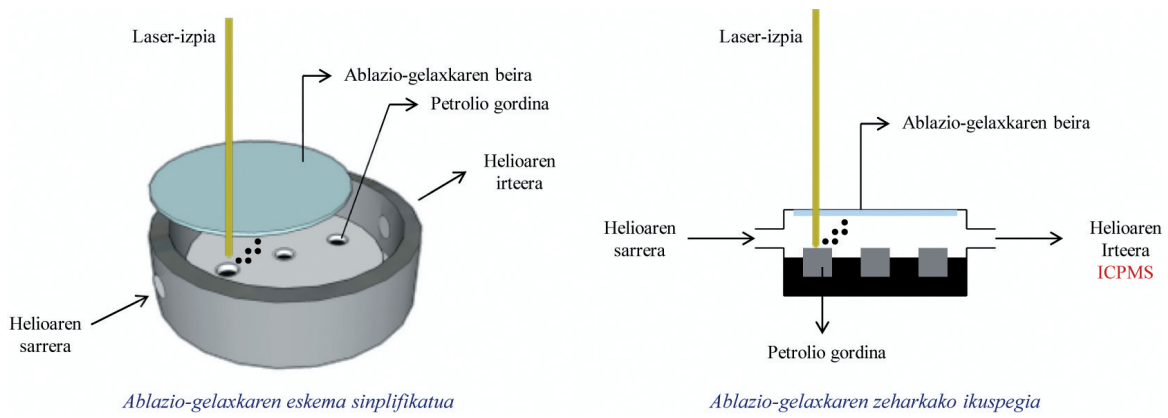

7. irudia. Petrolioaren ablazioaren eskema Ricard eta lankideek diseinatutako ablazio-gelaxka [65]. 
N. Grijalba, F. Claverie, A. Donard , H. Tabouret, C. Pecheyran, N. Unceta, M. A. Goicolea, R.J. Barrio

ICPMSa petrolioaren analisirako asko erabili den teknika da, baina, lagin organikoa izanik, analisia arretaz egitea ezinbestekoa da: alde batetik, laginaren mineralizazioa luzea, neketsua eta askotan amaigabea da; bestalde, lagina zuzenean ICPMSan sartzean plasma ezegonkortu eta itzali dezake. Gainera, plasman laginaren errekuntza egokia ez bada, karbonozko metakinak sor daitezke kono eta lenteetan eta ioien erauzketaren eraginkortasuna eta seinalearen intentsitatea murriztu $[68,69]$.

Laser bidezko ablazioa lagin likido organikoen analisirako berriki erabilitako etorkizun handiko teknika da (7. irudia). Halere, teknika honek zenbait eragozpen baditu, besteak beste, petrolio-zipriztinek ablazio-kamera zikindu dezakete eta petrolio-metakinek LA-ICPMS transferentzia sistema blokea dezakete. Arazo horiei irtenbidea emateko ablazio-angelua aldatu edo zelulosa ehun batean absorbatutako lagina ablaziona daiteke [70].

\subsection{Auzitegiko ikerketa}

\subsubsection{Tiro-aztarnen identifikazioa}

Su-armen erabilpena modu kezkagarrian igo da gure gizartean eta horrek tiro egin ondoren sortutako partikulen analisirako metodologia analitiko berriak garatzea ekarri du. Tiro-aztarnak (gunshot residue, GSR) arma kliskatu bezain azkar eta munizioaren errekuntza prozesuaren ondorioz sortutako partikula sorta da $[71,72]$. Krimen agertokian tiro-aztarnak osatzen dituzten konposatuen detekzioak eta identifikazioak su-armen erabileraren ebidentzia fidagarria eskaintzen du. Hala ere, auzitegi-analisiaren ikuspuntutik, su-arma bat ustez kliskatu duen pertsona baten identifikazioa argitzeko, ezinbestekoa da bere gorputzean aurki daitezkeen tiro-aztarnak ziurtasun osoz identifikatzea [73].

Gaur egun, auzitegiaren ikuspuntutik baliagarria den teknika analitiko bakarra da X izpien energia dispertsiboaren espektroskopiari akoplatutako ekorketa bidezko mikroskopia elektronikoa (SEM-EDX). Teknika horrek partikulen morfologia eta konposizio ez-organikoari buruzko aldibereko informazioa eskaintzen du. Hala ere, teknika horrek baditu zenbait desabantaila: analisi-denbora luzea (8 eta 10 ordu artean) eta laginketa-dispositiboan itsatsita gera daitezkeen azal, ile eta besteek partikulen bana-banako identifikazioa oztopa dezakete [74,75].

Hori dela eta, Abrego eta lankideek [76,77] tiro-partikulen zalantzarik gabeko identifikazioa egiteko LA-ICPMS teknikan oinarritutako metodoa garatu dute, laginaren aurretratamendurik behar ez duena eta analisi-denbora nabarmenki murrizten duena (66 min), eta horrela, SEM-EDX teknikak dituen desabantailak gainditu. Metodo horretan, tiro-aztarnen laginketarako karbonozko zinta itsaskorra erabiltzen da eta laserra gainazaletik 
abiadura jakin batekin desplazatzen da, sigi-saga erako patroi bat jarraituz. ICPMSan analizatzean denborarekiko aldakorra den seinalearen erregistro bat lortzen da. Tiro-aztarnen partikula bereizgarriak ( $\mathrm{Pb}-\mathrm{Sb}-\mathrm{Ba})$ baldin badaude, hiru elementu horien seinaleak aldi berean agertu behar dira (8. irudia).

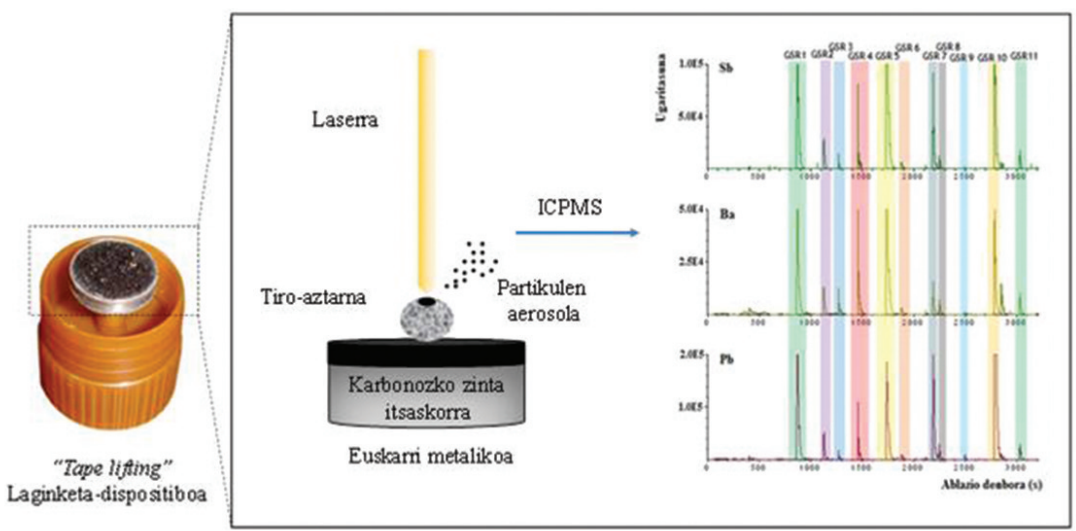

8. irudia. Laser-izpiak tiro-aztarnaren gain eragin eta materia erauzten du. Ondoren, ICPMS detektagailuan denborarekin aldakorra den seinalearen erregistroa lortzen da. $\mathrm{Sb}$, Ba eta $\mathrm{Pb}$ elementuen seinaleen aldibereko erregistroak partikula tiro-aztarna bati dagokiola egiaztatzen du.

\subsubsection{Material nuklearraren trafikoaren aurkako borroka}

1990. urteaz geroztik material nuklearraren legez kanpoko trafikoa areagotu egin da eta auzitegi-zientzia nuklearra deritzon zientzia analitikoaren sorreran lagundu du. Auzitegi-zientzia nuklearrak konfiskatutako material nuklear ez-legalari buruzko informazioa (jatorria eta erabilera-asmoa) eskaintzea du helburu. Informazio horrek berebiziko garrantzia du segurtasun nuklearra sustatzeko eta galerak edo lapurretak saihesteko [78,79]. Uranio-mea kontzentratua meategian bertan egindako aurrearazketa prozesuaren ondoren lortzen da eta, ondoren, instalazio nuklearretara garraiatzen da kontzentrazio prozesuarekin jarraitzeko. Uranioaren konposizio isotopikoa desberdina da ondoren izango duen erabileraren arabera (9. irudia). Ondorioz, markatzaileen identifikazioa beharrezkoa da material nuklearraren trazabilitatearen jarraipena egiteko [80]. Hori dela eta, gaiari buruz adituak direnek (JRC Institute for Transuranium Elements, JRC-ITU) funtsezkoak diren parametroen identifikazioaren eta ezarpenaren garrantzia azpimarratzen dute behin eta berriz [81]. 


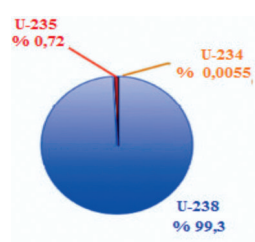

Uranio naturala $>\% 99,3$ U-238 $<\% 0,72$ U-235

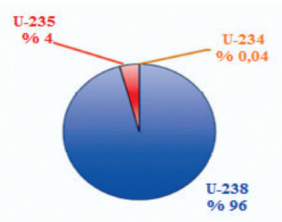

Partzialki aberastutako uranioa (erabilpen zibila, erreaktore nuklearrak) $\%$ 3-4 U-235

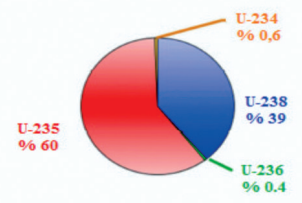

Erabat aberastutako uranioa (erabilpen militarra, arma nuklearrak) $>\% 60 \mathrm{U}-235$

9. irudia. Uranioaren konposizio isotopikoa erabileraren arabera.

Konfiskatutako material nuklearraren karakterizazio kimikoa egiteko giza aktibitateen aztarnak (fisiko zein kimikoak) edo erradiazio parametroak ikertzen dira. Adierazle guztien artean, lur arraroek (eskandioa (Sc), itrioa (Y), lantanidoak eta aktinidoak) oreetan duten banaketa aukera interesgarria da iturburua zehazteko, banaketa-patroiak mineralizazio prozesuarekin eta baldintza geologikoekin erlazio zuzena baitu. Elementu horiek mineralaren formazio prozesuan eransten dira eta banaketak egonkor irauten du mearen kontzentrazio-urratsean [82].

Auzitegiko zientzia nuklearraren eremuan eskuragai dagoen lagin-kantitatea arazoa da maiz. Gainera, azpilaginketak egitea beharrezkoa da analisi mota desberdinak egiteko eta, zoritxarrez, lagina berreskuratzea ahalbidetzen ez duten teknika analitiko suntsikorrak erabili ohi dira (laginaren mineralizazioa eta diluzioa, prezipitazio eta erauzketa, etab) [83]. LAICPMSaren erabilpenak, alabaina, nabarmen murrizten du analisian erabili beharreko lagin-kantitatea.

Beraz, LA-ICPMS teknikarekin egindako analisiak azkarrak eta errazak dira eta, gainera, analitoek laginean duten banaketari buruzko informazio espaziala ere eskaintzen du. Hau da, ore-nahasketa batean, analisia tamaina txikiko $(\mu \mathrm{m})$ partikula mailan egiteak iturburu desberdinak bereiztea ahalbidetzen du. Hori ezinezkoa izango litzateke ohizko analisi-teknikekin, zeinetan lagina bere osotasunean analizatzen den.

\section{ONDORIO OROKORRAK}

Laser bidezko ablazioa (LA) bi aplikazio alorretan erabiltzen da bereziki. Alde batetik, lagina osotasunean analizatu eta bereizmen espazial txikiko beharra duten (80-150 $\mu \mathrm{m}$-ko zulotxo diametroa) aplikazioetan eta bestetik, bereizmen espazial handia behar dutenetan. Laginetik erauzitako materia-kantitate txikia dela eta, sentikortasun handiko masa-espektrometroak behar dira. Laser bidezko ablazioa eta akoplamendu induktibozko plasma-masa espektrometriaren konbinazioa erakargarria da, sentikorta- 
Laser bidezko ablazioaren egungo egoera eta aplikazioak

sun handia eta abian jartzeko erraztasuna direla eta. Hortaz, laser bidezko ablazioa solidoen analisi zuzena egiteko, azken urteotan sakonki ikertu eta hobetu den laginketa-teknika da eta, gaur egun, erreferentziazko teknika gisa erabiltzen da laborategietan eguneroko lagin solidoen analisia egiteko.

\section{ESKER ONAK}

Egileek Eusko Jaurlaritzako Hezkuntza, Hizkuntza Politika eta Kultura Sailari Euskal Unibertsitate Sistemako ikerketa-taldeen jarduera bultzatzeko diru-laguntza eskertzen diote (METABOLOMIPs taldea GIC10/25). Nagore Grijalbak Université de Pau et Des Pays de L'Adourri (UPPA) eta Euskal Herriko Unibertsitateari (UPV/EHU) tutorekidetza erregimenean doktorego-tesia egiteko diru-laguntza eskertzen die.

\section{BIBLIOGRAFIA}

[1] FERNÁNDEZ, B.; CLAVERIE, F.; PÉCHEYRAN, C. eta DONARD, O.F.X. 2007. «Direct analysis of solid samples by fs-LA-ICP-MS». TrAC Trends in Analytical Chemistry, 26, 951-966.

[2] KOCH, J. eta GUNTHER, D. 2011. «Review of the state-of-the-art of laser ablation inductively coupled plasma mass spectrometry». Applied Spectroscopy, 65, 155-62.

[3] RUSSO, R.E.; MAO, X.; LIU, H.; GONZALEZ, J. eta MAO, S.S. 2002. «Laser ablation in analytical chemistry-a review». Talanta, 57, 425-451.

[4] VOELLKOPF, U.; PAUL, M. eta DENOYER, E.R. 1992. «Analysis of solid samples by ICP-mass spectrometry». Fresenius' Journal of Analytical Chemistry, 342, 917-923.

[5] KOSLER, J.; WIEDENBECK, M.; WIRTH, R.; HOVORKA, J.; SYLVESTER, P. eta MIKOVA, J. 2005. «Chemical and phase composition of particles produced by laser ablation of silicate glass and zircon-implications for elemental fractionation during ICP-MS analysis». Journal of Analytical Atomic Spectrometry, 20, 402-409.

[6] GUNTHER, D.; HORN, I. eta HATTENDORF, B. 2000. «Recent trends and developments in laser ablation-ICP-mass spectrometry». Fresenius J Anal Chem, 368, 4-14.

[7] HATTENDORF, B.; LATKOCZY, C. eta GÜNTHER, D. 2003. «Peer Reviewed: Laser Ablation-ICPMS». Analytical Chemistry, 75, 341 A-347 A.

[8] WATLING, R.J.; F. LYNCH, B. eta HERRING, D. 1997. «Use of Laser Ablation Inductively Coupled Plasma Mass Spectrometry for Fingerprinting Scene of Crime Evidence». Journal of Analytical Atomic Spectrometry, 12, 195-203. 
N. Grijalba, F. Claverie, A. Donard , H. Tabouret, C. Pecheyran, N. Unceta, M. A. Goicolea, R.J. Barrio

[9] TREJOS, T.; MONTERO, S. eta ALMIRALL, J.R. 2003. «Analysis and comparison of glass fragments by laser ablation inductively coupled plasma mass spectrometry (LA-ICP-MS) and ICP-MS». Anal Bioanal Chem, 376, 1255-64.

[10] DURRANT, S.F. eta WARD, N.I. 2005. «Recent biological and environmental applications of laser ablation inductively coupled plasma mass spectrometry (LA-ICP-MS)». Journal of Analytical Atomic Spectrometry, 20, 821-829.

[11] LIU, Y.; HU, Z.; LI, M. eta GAO, S. 2013. «Applications of LA-ICP-MS in the elemental analyses of geological samples». Chinese Science Bulletin, 58, 3863-3878.

[12] NEFF, H. 2012. «Laser Ablation ICP-MS in Archaeology». Mass Spectrometry Handbook. John Wiley \& Sons, Inc.

[13] KUHN, H.R. eta GUNTHER, D. 2003. «Elemental fractionation studies in laser ablation inductively coupled plasma mass spectrometry on laser-induced brass aerosols». Analytical Chemistry, 75, 747-53.

[14] LOEWEN, M.W. eta KENT, A.J.R. 2012. «Sources of elemental fractionation and uncertainty during the analysis of semi-volatile metals in silicate glasses using LA-ICP-MS». Journal of Analytical Atomic Spectrometry, 27, 1502-1508.

[15] RUSSO, R.E.; MAO, X.L.; LIU, C. eta GONZALEZ, J. 2004. «Laser assisted plasma spectrochemistry: laser ablation». Journal of Analytical Atomic Spectrometry, 19, 1084-1089.

[16] BECKER, J.S. 2002. «Applications of inductively coupled plasma mass spectrometry and laser ablation inductively coupled plasma mass spectrometry in materials science». Spectrochimica Acta Part B: Atomic Spectroscopy, 57, 1805-1820.

[17] BECKER, J.S. eta DIETZE, H.J. 2000. «Inorganic mass spectrometric methods for trace, ultratrace, isotope, and surface analysis1». International Journal of Mass Spectrometry, 197, 1-35.

[18] HAHN, D.W. eta OMENETTO, N. 2010. «Laser-induced breakdown spectroscopy (LIBS), part I: review of basic diagnostics and plasma-particle interactions: still-challenging issues within the analytical plasma community». Appl Spectrosc, 64, 335-66.

[19] HAHN, D.W. eta OMENETTO, N. 2012. «Laser-induced breakdown spectroscopy (LIBS), part II: review of instrumental and methodological approaches to material analysis and applications to different fields». Appl Spectrosc, 66, 347-419.

[20] PAPAZOGLOU, D.G.; PAPADAKIS, V. eta ANGLOS, D. 2004. «In situ interferometric depth and topography monitoring in LIBS elemental profiling of multi-layer structures». Journal of Analytical Atomic Spectrometry, 19, 483-488.

[21] PISONERO, J.; FERNÁNDEZ, B.; PEREIRO, R.; BORDEL, N. eta SANZMEDEL, A. 2006. «Glow-discharge spectrometry for direct analysis of thin and ultra-thin solid films». TrAC Trends in Analytical Chemistry, 25, 11-18. 
Laser bidezko ablazioaren egungo egoera eta aplikazioak

[22] SANDERSON, N.E.; HALL, E.; CLARK, J.; CHARALAMBOUS, P. eta HALL, D. «Glow discharge mass spectrometry-a powerful technique for the elemental analysis of solids». Microchimica Acta, 91, 275-290.

[23] RENIERS, F. eta TEWELL, C. 2005. «New improvements in energy and spatial (x, y, z) resolution in AES and XPS applications». Journal of Electron Spectroscopy and Related Phenomena, 142, 1-25.

[24] WATTS, J.F. eta WOLSTENHOLME, J. 2003. «Electron Spectroscopy: Some Basic Concepts». An Introduction to Surface Analysis by XPS and AES. John Wiley \& Sons, Ltd,

[25] TSUJI, K.; NAKANO, K.; TAKAHASHI, Y.; HAYASHI, K. eta RO, C.-U. 2012. «X-ray Spectrometry». Analytical Chemistry, 84, 636-668.

[26] WEST, M.; ELLIS, A.T.; POTTS, P.J.; STRELI, C.; VANHOOF, C. eta WOBRAUSCHEK, P. 2014. "Atomic Spectrometry Update - a review of advances in X-ray fluorescence spectrometry». Journal of Analytical Atomic Spectrometry, 29, 1516-1563.

[27] WILLIAMS, P. 1985. «Secondary Ion Mass Spectrometry». Annual Review of Materials Science, 15, 517-548.

[28] HERRMANN, A.M.; RITZ, K.; NUNAN, N.; CLODE, P.L.; PETT-RIDGE, J.; KILBURN, M.R.; MURPHY, D.V.; O'DONNELL, A.G. eta STOCKDALE, E.A. 2007. «Nano-scale secondary ion mass spectrometry - A new analytical tool in biogeochemistry and soil ecology: A review article». Soil Biology and Biochemistry, 39, 1835-1850.

[29] FIGG, D. eta KAHR, M.S. 1997. «Elemental Fractionation of Glass Using Laser Ablation Inductively Coupled Plasma Mass Spectrometry». Applied Spectroscopy, 51, 1185-1192.

[30] FIGG, D.J.; CROSS, J.B. eta BRINK, C. 1998. «More investigations into elemental fractionation resulting from laser ablation-inductively coupled plasma-mass spectrometry on glass samples». Applied Surface Science, 127-129, 287-291.

[31] GRAY, A.L. 1985. «Solid sample introduction by laser ablation for inductively coupled plasma source mass spectrometry». Analyst, 110, 551-556.

[32] MARGETIC, V.; PAKULEV, A.; STOCKHAUS, A.; BOLSHOV, M.; NIEMAX, K. eta HERGENRÖDER, R. 2000. «A comparison of nanosecond and femtosecond laser-induced plasma spectroscopy of brass samples». Spectrochimica Acta Part B: Atomic Spectroscopy, 55, 1771-1785.

[33] MOZNA, V.; PISONERO, J.; HOLA, M.; KANICKY, V. eta GUNTHER, D. 2006. «Quantitative analysis of Fe-based samples using ultraviolet nanosecond and femtosecond laser ablation-ICP-MS». Journal of Analytical Atomic Spectrometry, 21, 1194-1201.

[34] GÜNTHER, D. eta HATTENDORF, B. 2005. «Solid sample analysis using laser ablation inductively coupled plasma mass spectrometry». TrAC Trends in Analytical Chemistry, 24, 255-265.

[35] KOCH, J.; VON BOHLEN, A.; HERGENRODER, R. eta NIEMAX, K. 2004. «Particle size distributions and compositions of aerosols produced by 
N. Grijalba, F. Claverie, A. Donard , H. Tabouret, C. Pecheyran, N. Unceta, M. A. Goicolea, R.J. Barrio

near-IR femto- and nanosecond laser ablation of brass». Journal of Analytical Atomic Spectrometry, 19, 267-272.

[36] WANG, Z.; HATTENDORF, B. eta GÜNTHER, D. 2006. «Analyte Response in Laser Ablation Inductively Coupled Plasma Mass Spectrometry». Journal of the American Society for Mass Spectrometry, 17, 641-651.

[37] HERGENRODER, R.; SAMEK, O. eta HOMMES, V. 2006. «Femtosecond laser ablation elemental mass spectrometry». Mass Spectrometry Reviews, 25, 551-72.

[38] DONARD, C.P.A.S.C.A.P.C.A.E.M.A.O.F.X. 2007. «High repetition rate and low energy femtosecond laser ablation coupled to ICPMS detection: a new analytical approach for trace element determination in solid samples». Journal of Physics: Conference Series, 59, 112.

[39] GONZALEZ, J.J.; OROPEZA, D.; MAO, X. eta RUSSO, R.E. 2008. «Assessment of the precision and accuracy of thorium $(232 \mathrm{Th})$ and uranium (238U) measured by quadrupole based inductively coupled plasma-mass spectrometry using liquid nebulization, nanosecond and femtosecond laser ablation». Journal of Analytical Atomic Spectrometry, 23, 229-234.

[40] KOCH, J. eta GUNTHER, D. 2007. «Femtosecond laser ablation inductively coupled plasma mass spectrometry: achievements and remaining problems». Analytical and Bioanalytical Chemistry, 387, 149-53.

[41] HORN, I. eta GÜNTHER, D. 2003. «The influence of ablation carrier gasses $\mathrm{Ar}, \mathrm{He}$ and $\mathrm{Ne}$ on the particle size distribution and transport efficiencies of laser ablation-induced aerosols: implications for LA-ICP-MS». Applied Surface Science, 207, 144-157.

[42] ARROWSMITH, P. eta HUGHES, S.K. 1988. «Entrainment and Transport of Laser Ablated Plumes for Subsequent Elemental Analysis». Applied Spectroscopy, 42, 1231-1239.

[43] TESCH, F.W. eta THORPE, J.E. 2003. «Harvest and Environmental Relationships». The Eel. Blackwell Science Ltd., New Jersey.

[44] ARAI, T. eta HIRATA, T. 2006. «Differences in the Trace Element Deposition in Otoliths Between Marine- and Freshwater-resident Japanese Eels, Anguilla japonica, as Determined by Laser Ablation ICPMS». Environmental Biology of Fishes, 75, 173-182.

[45] TESCH, F.W. eta THORPE, J.E. 2003. «Post-Larval Ecology and Behaviour». The Eel. Blackwell Science Ltd., New Jersey.

[46] CAMPANA, S.E. eta THORROLD, S.R. 2001. «Otoliths, increments, and elements: keys to a comprehensive understanding of fish populations?» Canadian Journal of Fisheries and Aquatic Sciences, 58, 30-38.

[47] TESCH, F.W. eta THORPE, J.E. 2003. «Developmental Stages and Distribution of the Eel Species». The Eel. Blackwell Science Ltd., New Jersey.

[48] KENNEDY, B.P.; KLAUE, A.; BLUM, J.D.; FOLT, C.L. eta NISLOW, K.H. 2002. «Reconstructing the lives of fish using Sr isotopes in otoliths». Canadian Journal of Fisheries and Aquatic Sciences, 59, 925-929. 
Laser bidezko ablazioaren egungo egoera eta aplikazioak

[49] TABOURET, H.; BAREILle, G.; ClAVERIE, F.; PECHEYRAN, C.; PROUZET, P. eta DONARD, O.F. 2010. «Simultaneous use of strontium:calcium and barium:calcium ratios in otoliths as markers of habitat: application to the European eel (Anguilla anguilla) in the Adour basin, South West France». Marine Environmental Research, 70, 35-45.

[50] HOLÁ, M.; KALVODA, J.; BÁBEK, O.; BRZOBOHATÝ, R.; HOLOUBEK, I.; KANICKÝ, V. eta SKODA, R. 2008. «LA-ICP-MS heavy metal analyses of fish scales from sediments of the Oxbow Lake Certak of the Morava River (Czech Republic)». Environmental Geology, 58, 141-151.

[51] MCCULLOCH, M.; FALLON, S.; WYNDHAM, T.; HENDY, E.; LOUGH, J. eta BARNES, D. 2003. «Coral record of increased sediment flux to the inner Great Barrier Reef since European settlement». Nature, 421, 727.

[52] BARATS, A.; PÉCHEYRAN, C.; AMOUROUX, D.; DUBASCOUX, S.; CHAUVAUD, L. eta DONARD, O.F.X. 2007. «Matrix-matched quantitative analysis of trace-elements in calcium carbonate shells by laser-ablation ICP-MS: application to the determination of daily scale profiles in scallop shell (Pecten maximus)». Analytical and Bioanalytical Chemistry, 387, 1131-1140.

[53] UGARTE, A.; UNCETA, N.; PECHEYRAN, C.; GOICOLEA, M.A. eta BARRIO, R.J. 2011. «Development of matrix-matching hydroxyapatite calibration standards for quantitative multi-element LA-ICP-MS analysis: application to the dorsal spine of fish». Journal of Analytical Atomic Spectrometry, 26, 1421-1427.

[54] RUIZ, M.; RODRÍGUEZ-MARÍN, E. eta LANDA, J. Protocol for sampling of hard parts for bluefin tuna (Thunnus tuna) growth studies. Spain, Instituto Español de Oceanografía. Centro Oceanográfico de Santander.

[55] BECKER, J.S. 2010. «Imaging of metals, metalloids, and non-metals by laser ablation inductively coupled plasma mass spectrometry (LA-ICP-MS) in biological tissues». Methods in Molecular Biology, 656, 51-82.

[56] BECKER, J.S.; ZORIY, M.; BECKER, J.S.; DOBROWOLSKA, J.; DEHNHARDT, M. eta MATUSCH, A. 2007. «Elemental imaging mass spectrometry of thin sections of tissues and analysis of brain proteins in gels by laser ablation inductively coupled plasma mass spectrometry». Physica Status Solidi (c), 4, 1775-1784.

[57] CLARKSON, T.W. 1987. «Metal toxicity in the central nervous system». Environmental Health Perspectives, 75, 59-64.

[58] GAETA, A. eta HIDER, R.C. 2005. «The crucial role of metal ions in neurodegeneration: the basis for a promising therapeutic strategy». British Journal of Pharmacology, 146, 1041-59.

[59] ASCHNER, M.; ERIKSON, K.M.; HERRERO HERNANDEZ, E. eta TJALKENS, R. 2009. «Manganese and its role in Parkinson's disease: from transport to neuropathology». Neuromolecular Medicine, 11, 252-66.

[60] GUILARTE, T.R. 2010. «Manganese and Parkinson's disease: a critical review and new findings». Environmental Health Perspectives, 118, 1071-80. 
N. Grijalba, F. Claverie, A. Donard , H. Tabouret, C. Pecheyran, N. Unceta, M. A. Goicolea, R.J. Barrio

[61] OLANOW, C.W. 2004. «Manganese-induced parkinsonism and Parkinson's disease». Annals of the New York Academy of Science, 1012, 209-23.

[62] BUSH, A.I. 2013. «The metal theory of Alzheimer's disease». Journal of Alzheimer's Disease, 33 Suppl 1, S277-81.

[63] SCHRAG, M.; MUELLER, C.; OYOYO, U.; SMITH, M.A. eta KIRSCH, W.M. 2011. «Iron, zinc and copper in the Alzheimer's disease brain: a quantitative meta-analysis. Some insight on the influence of citation bias on scientific opinion». Progress in Neurobiology, 94, 296-306.

[64] BECKER, J.S.; ZORIY, M.V.; DEHNHARDT, M.; PICKHARDT, C. eta ZILLES, K. 2005. «Copper, zinc, phosphorus and sulfur distribution in thin section of rat brain tissues measured by laser ablation inductively coupled plasma mass spectrometry: possibility for small-size tumor analysis». Journal of Analytical Atomic Spectrometry, 20, 912-917.

[65] BECKER, J.S.; ZORIY, M.; BECKER, J.S.; DOBROWOLSKA, J. eta MATUSCH, A. 2007. «Laser ablation inductively coupled plasma mass spectrometry (LA-ICP-MS) in elemental imaging of biological tissues and in proteomics». Journal of Analytical Atomic Spectrometry, 22, 736-744.

[66] FELDMANN, J.; KINDNESS, A. eta EK, P. 2002. «Laser ablation of soft tissue using a cryogenically cooled ablation cell». Journal of Analytical Atomic Spectrometry, 17, 813-818.

[67] RICARD, E.; PECHEYRAN, C.; SANABRIA ORTEGA, G.; PRINZHOFER, A. eta DONARD, O.F. 2011. " Direct analysis of trace elements in crude oils by high-repetition-rate femtosecond laser ablation coupled to ICPMS detection «. Analytical and Bioanalytical Chemistry, 399, 2153-2165.

[68] HAUSLER, D. 1987. «Trace element analysis of organic solutions using inductively coupled plasma-mass spectrometry». Spectrochimica Acta Part B: Atomic Spectroscopy, 42, 63-73.

[69] HUTTON, R.C. 1986. «Application of inductively coupled plasma source mass spectrometry (ICP-MS) to the determination of trace metals in organics». Journal of Analytical Atomic Spectrometry, 1, 259-263.

[70] FICHET, P.; MAUCHIEN, P.; WAGNER, J.-F. eta MOULIN, C. 2001. «Quantitative elemental determination in water and oil by laser induced breakdown spectroscopy». Analytica Chimica Acta, 429, 269-278.

[71] DALBY, O.; BUTLER, D. eta BIRKETT, J.W. 2010. «Analysis of gunshot residue and associated materials--a review». Journal of Forensic Science, 55, 924-43.

[72] SAVERIO ROMOLO, F. eta MARGOT, P. 2001. «Identification of gunshot residue: a critical review». Forensic Science International, 119, 195-211.

[73] CHANG, K.H.; JAYAPRAKASH, P.T.; YEW, C.H. eta ABDULLAH, A.F.L. 2013. «Gunshot residue analysis and its evidential values: a review». Australian Journal of Forensic Sciences, 45, 3-23.

[74] ZEICHNER, A. 2001. «Is there a real danger of concealing gunshot residue (GSR) particles by skin debris using the tape-lift method for sampling GSR from hands?» Journal of Forensic Science, 46, 1447-55. 
Laser bidezko ablazioaren egungo egoera eta aplikazioak

[75] ZEICHNER, A. 2003. «Recent developments in methods of chemical analysis in investigations of firearm-related events». Analytical and Bioanalytical Chemistry, 376, 1178-1191.

[76] ABREGO, Z.; GRIJALBA, N.; UNCETA, N.; MAGUREGUI, M.; SANCHEZ, A.; FERNANDEZ-ISLA, A.; GOICOLEA, M.A. eta BARRIO, R.J. 2014. «A novel method for the identification of inorganic and organic gunshot residue particles of lead-free ammunitions from the hands of shooters using scanning laser ablation-ICPMS and Raman micro-spectroscopy». Analyst, 139, 6232-41.

[77] ABREGO, Z.; UGARTE, A.; UNCETA, N.; FERNANDEZ-ISLA, A.; GOICOLEA, M.A. eta BARRIO, R.J. 2012. «Unambiguous characterization of gunshot residue particles using scanning laser ablation and inductively coupled plasma-mass spectrometry». Analytical Chemistry, 84, 2402-9.

[78] MAYER, K.; WALLENIUS, M. eta FANGHÄNEL, T. 2007. «Nuclear forensic science-From cradle to maturity». Journal of Alloys and Compounds, 444-445, 50-56.

[79] MAYER, K.; WALLENIUS, M. eta RAY, I. 2005. «Nuclear forensics-a methodology providing clues on the origin of illicitly trafficked nuclear materials». Analyst, 130, 433-441.

[80] DONARD, A.; POTTIN, A.C.; POINTURIER, F. eta PECHEYRAN, C. 2015. «Determination of relative rare earth element distributions in very small quantities of uranium ore concentrates using femtosecond UV laser ablation - SF-ICP-MS coupling». Journal of Analytical Atomic Spectrometry, 30, 2420-2428.

[81] MAYER, K.; WALLENIUS, M. eta VARGA, Z. 2013. «Nuclear Forensic Science: Correlating Measurable Material Parameters to the History of Nuclear Material». Chemical Reviews, 113, 884-900.

[82] VARGA, Z.; WALLENIUS, M. eta MAYER, K. 2010. «Origin assessment of uranium ore concentrates based on their rare-earth elemental impurity pattern». Radiochimica Acta, 98, 771-778.

[83] KRAJKO, J.; VARGA, Z.; WALLENIUS, M. eta MAYER, K. 2015. «Development of a versatile sample preparation method and its application for rare-earth pattern and $\mathrm{Nd}$ isotope ratio analysis in nuclear forensics». Journal of Radioanalytical and Nuclear Chemistry, 304, 177-181. 